\title{
Does TAVI make you smarter? Exploring the effects of Transcatheter Aortic Valve Implantation on Cognitive Function
}

\author{
Marc P Pelletier ${ }^{1 *}$, Heather Le Blanc ${ }^{2}$, Alexandra M Yip ${ }^{2}$, Brian Archer ${ }^{2}$, Darren Ferguson ${ }^{2}$, Rand Forgie ${ }^{2}$, \\ Vernon Paddock², Ansar Hassan ${ }^{2}$ and Claudia L Cote ${ }^{3}$ \\ ${ }^{*}$ Brigham and Women's Hospital, Harvard Medical School, USA \\ ${ }^{2}$ Cardiovascular Research New Brunswick, New Brunswick Heart Center, Saint John Regional Hospital, Canada \\ ${ }^{3}$ Division of Cardiac Surgery, Department of Surgery, Dalhousie University, Canada
}

Submission: December 20, 2016; Published: January 05, 2017

*Corresponding author: Marc Pelletier, Brigham and Women's Hospital, 75 Francis St., Boston, Massachusetts, USA, 02115, 0ffice: 617-732-

7678; Fax: 617-732-6559; Email: MPPelletier@partners.org

Abstract

Background: Tran catheter aortic valve implantation (TAVI) is an alternative to surgical aortic valve replacement in high-risk patients. While early cognitive decline is commonly seen in patients undergoing cardiac surgery, the effect of TAVI on cognitive function is less well understood. The purpose of this study was to evaluate the effect of TAVI on cognitive function.

Methods: A prospective cohort study, evaluating 91 patients undergoing TAVI between September 2010 and September 2014 was performed. Cognitive function was assessed using the Montreal Cognitive Assessment (MoCA) prior to TAVI and at 6 months follow-up. MoCA is a comprehensive test that assesses a variety of cognitive domains including visuospatial/executive, naming, memory, attention, language, abstraction and orientation.

Results: Mean age was 79.2 years ( $\mathrm{SD} \pm 8.8$ ) and median Society of Thoracic Surgeon mortality risk was 6.5\% (IQR 4.3-11.0\%). Overall cognitive function, expressed as a median MoCA score [IQR], did not differ prior to TAVI as compared to 6 months following the procedure (24 $[22,26]$ vs. $25[22,27])(p=0.13)$. However, in subgroup analysis of patients who were cognitively impaired at baseline, a significant increase in their overall MoCA score was noted $(22[20,24]$ vs. $23[21,25])(p=0.03)$.

Conclusion: In a high-risk surgical cohort, overall cognitive function remained unchanged 6 months following TAVI. However, among patients with cognitive impairment at baseline, an improvement in overall cognitive function was noted following TAVI.

Keywords: Trans catheter valve; cognition; Montreal Cognitive Assessment

Abbreviations: TAVI: Tran catheter Aortic Valve Implantation; MoCA: Montreal Cognitive Assessment; CABG: Coronary Artery Bypass Graft; STS: Society of Thoracic Surgeons; AVA: Aortic Valve Area; NYHA: New York Heart Association; DASI: Duke Activity Status Index; DW-MRI: DiffusionWeighted MRI; MMSE: Mini Mental Status Examination; NINDS-CSN: National Institute of Neurologic Disorders and Stroke-Canadian Stroke Network

\section{Introduction}

Tran catheter aortic valve implantation (TAVI) has emerged as a superior alternative to medical therapy in patients with severe symptomatic aortic stenosis who are high risk for standard surgical aortic valve replacement [1]. Patients undergoing cardiac surgery frequently experience postoperative cognitive decline [2-5]. Whether or not TAVI patients experience a similar decline in cognitive function as found in patients undergoing cardiac surgery is unclear. Multiple studies have evaluated cognitive function in patients undergoing TAVI at various ranges of follow-up with differing measures of cognitive function [6-14], making conclusions from systematic reviews difficult to interpret [15].

Few studies [16-19] have used the Montreal Cognitive Assessment (MoCA), a more sensitive tool for cognitive 
impairment, which is recommended by the National Institute of Neurologic Disorders and Stroke-Canadian Stroke Network (NINDS-CSN) in this patient population. Previous studies using MoCA have demonstrated improvement, however they are limited by short duration of follow up [17-19] and small sample size [16]. Understanding the effects of TAVI on cognitive function will help the treating team in its approach to optimal patient selection and also in the prediction of patient outcomes following TAVI procedures. The purpose of this study was to determine the effect of TAVI on cognitive function at 6 months using the MoCA.

\section{Material and Methods}

\section{Patient Population}

The study cohort consisted of all patients undergoing TAVI for treatment of severe aortic stenosis from September 2010 until September 2014 at a single institution. Patients were selected to undergo TAVI by an interdisciplinary TAVI team on the basis of surgical risk and comorbid disease burden. Severe aortic stenosis was defined as an aortic valve area $<1.0 \mathrm{~cm} 2$ and/or an aortic valve mean gradient of $>40 \mathrm{mmHg}$ and/or a peak aortic velocity of $>4.0 \mathrm{~m} / \mathrm{sec}$. The study was approved by the Horizon Health Network Research Ethics Board. All patients consented to be included in the New Brunswick Heart Centre's TAVI registry.

\section{TAVI Procedure}

All procedures were performed by a dedicated institutional TAVI team, which included members from the departments of cardiac surgery, interventional cardiology, interventional radiology, and cardiacanaesthesia. All procedures were performed under general anaesthesia with standard hemodynamic monitoring and transesophageal echocardiography. Most cases utilized transfemoralor transapical access with a smaller number of cases being performed via a transaortic or axillary approach. In all cases, pre-dilatation of the aortic valve was performed under rapid pacing. The valves used included the Sapien and Sapien XT balloon-expandable valves (Edwards Life sciences, Inc., Irvine, $\mathrm{CA}$ ) and the Portico self-expanding valve (St. Jude Medical, Inc., St. Paul, MN).All patients were transferred to the intensive care unit following the procedure for monitoring.

\section{Baseline Assessment}

Data regarding the following baseline characteristics were collected: age, sex,smoking history, diabetes, dyslipidemia, hypertension, peripheral vascular disease, stroke, transient ischemic attack, renal failure, pulmonary disease, atrial fibrillation or flutter, hospitalization for aortic stenosis in previous 6 months, previous Percutaneous coronary intervention, previous coronary artery bypass graft (CABG) surgery, previous pacemaker or implantable cardiac defibrillator insertion, residential status (home independent, home dependent, assisted living, hospital), and surgical risk as determined by the Society of Thoracic Surgeons (STS) Score. Echocardiographic evaluation of aortic annulus size, aortic valve area (AVA), aortic peak gradient, aortic mean gradient, and ejection fraction prior to surgery was also performed. Baseline functional status was assessed using the New York Heart Association (NYHA) classification, while baseline physical function was assessed using the Duke Activity Status Index (DASI).

MoCA is a questionnaire-based tool with a maximum score of 30 , was used to assess baseline cognition. The MoCA score is calculated based on a combined score obtained in the following domains: visuospatial/executive (/5), naming (/3), attention $(/ 6)$, language $(/ 3)$, abstraction $(/ 2)$, delayed recall $(/ 5)$, and orientation (/6). A MoCA score of $\geq 26$ is considered normal [20], while patients with a MoCA score $<26$ are considered to be cognitively impaired. Education level was adjusted for by allocating an additional point to patients who had not achieved grade 12 or equivalent. The Blind MoCA, adapted for the visually impaired, omits visuospatial/executive (/5) and naming (/3), giving a combined maximal score of 22 , with a score $\geq 18$ being considered normal, and scores $<18$ considered cognitively impaired at baseline.

\section{Patient Follow Up}

Patients were evaluated in the TAVI clinic at 6 months for evaluation of functional status, physical function and cognitive function.

\section{Statistical Analysis}

Descriptive statistics of the sample consisted of means and standard deviations for normally distributed continuous variables, medians and interquartile ranges for non-normally distributed continuous variables, and counts and proportions for categorical variables. Characteristics of patients with normal vs. impaired cognition at baseline were compared using Wilcoxon-Mann-Whitney tests, chi-squared tests, and Fisher's exact tests as appropriate. Baseline and 6-month follow-up measures of functional status, physical function and cognition were compared using the Wilcoxon signed-rank test to account for the repeated measures design and non-normal distribution of the data. P-values $<0.05$ were considered significant. All statistical analyses were performed using the SAS statistical software package, v9.3 (Cary, North Carolina).

\section{Results}

A total of 127 patients were consented for a TAVI procedure between September 2010 and September 2014. Of these patients, 3 patients were converted to surgical aortic valve replacement, 4 patients had the procedure aborted due to technical reasons or complications, 5 patients expired before the 6 month follow up, 1 patient had the device explanted 2 months after the procedure, 2 patients did not complete the baseline MoCA assessment, 12 patients were followed up via the province's tele health system and as such did not complete the 6 month MoCA, and 9 patients refused follow up. The remaining 91 patients formed the final study population. 


\section{Journal of Cardiology \& Cardiovascular Therapy}

Of the 91 patients, $70 \%$ of patients [64] underwent TAVI by via the transfemoral approach, $29 \%$ of patients [26] via the transapical approach, and $1 \%$ of patients [1] via the subclavian approach. The Sapien and Sapien XT balloon-expandable valves (Edwards Life sciences, Inc., Irvine, CA) were used in 95\% of patients [86], while the Portico self-expanding valve (St. Jude Medical, Inc., St. Paul, MN) was used in 5\% of patients [5].

Mean age was 79.2 years $(S D \pm 8.8)$ and median Society of Thoracic Surgeons mortality risk was 6.5\% (IQR 4.3-11.0\%)
(Table 1). The blind MoCA was used for 3 patients both at baseline and following TAVI. The remaining patients completed the full MoCA. At baseline $40.6 \%$ of patients [37] were found to have normal cognition while $59.3 \%$ of patients [54] were found to be mildly cognitively impaired. When compared to patients with normal cognition, cognitively impaired patients were significantly older and had higher STS scores (Table 1). Otherwise, no significant differences existed. In both patient subgroups, TAVI resulted in a significant improvement in functional status and physical function (Table 2).

Table 1: Baseline Characteristics (BMI, Body Mass Index; PCI, Percutaneous Coronary Intervention; CABG, Coronary Artery Bypass Graft; ICD, Implantable Cardiac Defibrillator; STS, Society of Thoracic Surgeons).

\begin{tabular}{|c|c|c|c|c|}
\hline Patient Characteristics & All & Impaired $(n=37)$ & Not impaired $(n=54)$ & p-value \\
\hline Age, years, median [IQR] & $80[74,86]$ & $73[68,80]$ & $83.5[79,87]$ & $<0.0001$ \\
\hline Female, n (\%) & $44(48)$ & $18(49)$ & $26(48)$ & 0.96 \\
\hline Smoking, n (\%) & & & & 0.95 \\
\hline Never & $39(43)$ & $15(41)$ & $24(44)$ & \\
\hline Former & $45(49)$ & $19(51)$ & $26(48)$ & \\
\hline Current & $7(8)$ & $3(8)$ & $4(7)$ & \\
\hline $\mathrm{BMI}, \mathrm{kg} / \mathrm{m}^{2}$, median, [IQR] & $27.4[23.4,31.9]$ & $28.5[24.9,35.2]$ & $26.5[22.9,29.7]$ & 0.10 \\
\hline Diabetes, n (\%) & $35(38)$ & $17(46)$ & $18(33)$ & 0.22 \\
\hline Dyslipidemia, n (\%) & $69(76)$ & $31(84)$ & $38(70)$ & 0.14 \\
\hline Hypertension, n (\%) & $77(85)$ & $32(86)$ & $45(83)$ & 0.68 \\
\hline $\begin{array}{c}\text { Peripheral vascular } \\
\text { disease, } \mathrm{n}(\%)\end{array}$ & $29(32)$ & $15(41)$ & $14(26)$ & 0.14 \\
\hline Stroke, n (\%) & $8(9)$ & $3(8)$ & $5(9)$ & 1.00 \\
\hline $\begin{array}{c}\text { Transient ischemic attack, } \\
\mathrm{n}(\%)\end{array}$ & $9(10)$ & $3(8)$ & $6(11)$ & 0.73 \\
\hline Renal failure, n (\%) & $55(60)$ & $20(54)$ & $35(65)$ & 0.30 \\
\hline Pulmonary disease, n (\%) & $42(46)$ & $17(46)$ & $25(46)$ & 0.97 \\
\hline $\begin{array}{l}\text { Atrial fibrillation or flutter, } \\
\mathrm{n}(\%)\end{array}$ & $28(31)$ & $9(24)$ & $19(35)$ & 0.27 \\
\hline $\begin{array}{l}\text { Hospitalization for AS } \\
\text { previous } 6 \text { months, n (\%) }\end{array}$ & $42(46)$ & $16(43)$ & $26(48)$ & 0.64 \\
\hline Previous PCI, n (\%) & $16(18)$ & $8(22)$ & $8(15)$ & 0.40 \\
\hline Previous CABG, n (\%) & $33(36)$ & $17(46)$ & $16(30)$ & 0.11 \\
\hline $\begin{array}{c}\text { Pacemaker/ICD Implant, } \\
\mathrm{n}(\%)\end{array}$ & $12(13)$ & $3(8)$ & $9(17)$ & 0.35 \\
\hline Residential Status, n (\%) & & & & 0.37 \\
\hline home independent & $75(82)$ & $33(89)$ & $42(78)$ & \\
\hline home dependent & $4(4)$ & $2(5)$ & $2(4)$ & \\
\hline assisted living & $6(7)$ & $1(3)$ & $5(9)$ & \\
\hline hospital & $6(7)$ & $1(3)$ & $5(9)$ & \\
\hline STS score, median [IQR] & $6.5[4.3,11.0]$ & $6.0[3.2,7.5]$ & $7.6[4.8,13.3]$ & 0.005 \\
\hline Aortic Valve Area, $\mathrm{cm}^{2}$ & $0.70[0.58,0.77]$ & $0.70[0.60,0.80]$ & $0.63[0.53,0.72]$ & 0.08 \\
\hline $\begin{array}{l}\text { Aortic Valve Peak Gradient, } \\
\text { mmHg }\end{array}$ & $80[63,94]$ & $80[54,91]$ & $80[64,94]$ & 0.43 \\
\hline $\begin{array}{l}\text { Aortic Valve Mean } \\
\text { Gradient, mmHg }\end{array}$ & $46[35,57]$ & $45[33,57]$ & $46[36,56]$ & 0.42 \\
\hline Ejection Fraction, \% & $60[45,65]$ & $55[40,60]$ & $60[50,65]$ & 0.36 \\
\hline
\end{tabular}


Table 2: Baseline and 6-month functional status and physical function.

\begin{tabular}{|c|c|c|c|}
\hline Outcome, median [IQR] & Baseline & 6 months & p-value \\
\hline \multicolumn{4}{|c|}{ All patients, $n=91$} \\
\hline NYHA Functional Class & $3[3,4]$ & $1[1,2]$ & $<0.0001$ \\
\hline Duke Activity Status Index & $16.0[13.0,21.0]$ & $21.2[17.7,25.7]$ & $<0.0001$ \\
\hline \multicolumn{4}{|c|}{ Normal Cognition, $\mathrm{n}=37$} \\
\hline NYHA Functional Class & $3[2,3]$ & $1[1,2]$ & $<0.0001$ \\
\hline Duke Activity Status Index $(n=35)$ & $17.3[14.2,21.0]$ & $23.1[19.7,25.7]$ & $<0.0001$ \\
\hline \multicolumn{4}{|c|}{ Impaired Cognition, $n=54$} \\
\hline NYHA Functional Class & $3[3,4]$ & $1[1,2]$ & $<0.0001$ \\
\hline Duke Activity Status Index $(n=51)$ & $15.0[13.0,20.0]$ & $18.8[15.4,23.1]$ & $<0.0001$ \\
\hline
\end{tabular}

Table 3: Baseline and 6-month follow up cognitive assessment.

\begin{tabular}{|c|c|c|c|}
\hline MOCA, median [IQR] & Baseline & 6 months & p-value \\
\hline \multicolumn{4}{|c|}{ All patients, $n=91$} \\
\hline Overall & $24[22,26]$ & $25[22,27]$ & 0.13 \\
\hline Visuospatial/Executive ( $\mathrm{n}=88$ ) & $4[3,5]$ & $4[4,5]$ & 0.14 \\
\hline Naming $(\mathrm{n}=88)$ & $3[2,3]$ & $3[2,3]$ & 0.86 \\
\hline Attention & $6[5,6]$ & $6[5,6]$ & 0.41 \\
\hline Language & $2[1,2]$ & $1[1,2]$ & 0.65 \\
\hline Abstraction & $2[1,2]$ & $2[1,2]$ & 0.74 \\
\hline Delayed Recall & $3[1,4]$ & $3[2,4]$ & 0.003 \\
\hline Orientation & $6[6,6]$ & $6[6,6]$ & 0.40 \\
\hline \multicolumn{4}{|c|}{ Normal Cognition, $n=37$} \\
\hline Overall & $27[26,28]$ & $27[24,28]$ & 0.55 \\
\hline Visuospatial/Executive $(\mathrm{n}=35)$ & $5[4,5]$ & $5[4,5]$ & 0.99 \\
\hline Naming $(\mathrm{n}=35)$ & $3[3,3]$ & $3[2,3]$ & 0.45 \\
\hline Attention & $6[6,6]$ & $6[6,6]$ & 0.09 \\
\hline Language & $2[1,3]$ & $2[1,3]$ & 0.61 \\
\hline Abstraction & $2[1,2]$ & $2[2,2]$ & 0.56 \\
\hline Delayed Recall & $4[4,5]$ & $4[3,5]$ & 0.86 \\
\hline Orientation & $6[6,6]$ & $6[6,6]$ & 1.00 \\
\hline \multicolumn{4}{|c|}{ Impaired Cognition, $n=54$} \\
\hline Overall & $22[20,24]$ & $23[21,25]$ & 0.03 \\
\hline Visuospatial/Executive $(\mathrm{n}=53$ ) & $4[3,4]$ & $4[4,4]$ & 0.06 \\
\hline Naming $(\mathrm{n}=53)$ & $3[2,3]$ & $3[2,3]$ & 0.47 \\
\hline Attention & $5.5[5,6]$ & $6[5,6]$ & 0.95 \\
\hline Language & $1[1,2]$ & $1[1,2]$ & 0.89 \\
\hline Abstraction & $2[1,2]$ & $1[1,2]$ & 0.43 \\
\hline Delayed Recall & $1.5[1,3]$ & $3[1,4]$ & 0.0001 \\
\hline Orientation & $6[6,6]$ & $6[6,6]$ & 0.38 \\
\hline
\end{tabular}

With respect to cognition, there was no significant change in overall cognitive status between baseline and6 months for either the entire cohort $(24[22,26]$ vs. $25[22.27], p=0.13)$ or for the cognitively intact group $(27[26,28]$ vs. $27[24,28], p=0.55)$ (Table 3). However, for patients who were already cognitively impaired at baseline $(\mathrm{MoCA}<26)$, there was a significant improvement in overall MoCA Score (22 [20.24] vs. 23 [21, 25], $\mathrm{p}=0.03$ )(Table 3 ). Analysis of sub domains of the MoCA score in this patient subgroup demonstrated a significant increase in delayed recall ability in cognitively impaired patients $(1.5[1,3]$ vs. $3[1,4], \mathrm{p}=0.0001$ ) with all other sub domains showing no significant change. 


\section{Discussion}

The purpose of this study was to determine the effect of TAVI on cognitive function. While this study demonstrated preservation in cognitive function following TAVI in patients with elevated surgical risk, it also founda statistically significant improvement in cognitive function among patients who were cognitively impaired at baseline.

Patients undergoing cardiac operations experience postoperative cognitive decline with rates ranging from $3 \%$ to $53 \%[4,5,21]$. Micro embolization has been detected using transcranial Doppler ultra sonography and magnetic resonance imaging in $15 \%$ to $47 \%$ of cardiac surgery patients [22-28] and has been associated with neuro cognitive decline [22,24,25]. However, other studies have found no association between new embolic lesions and postoperative decline [29], including a study evaluating patients undergoing aortic valve surgery [26].

Micro embolization during TAVI procedures has also been detected using transcranial Doppler evaluation [11] and magnetic resonance imaging studies [30-34]. In a prospective analysis of 125 patients undergoing TAVI, no association was found between silent infarcts detected by Diffusion-Weighted MRI (DW-MRI) and decline in neuropsychological status, measured using the repeatable battery for the assessment of neuropsychological status [33]. Similar studies have found no association between new DW-MRI lesions following TAVI and neuro cognitive decline as measured using the Mini Mental Status Examination (MMSE) $[11,12,14]$. This cohort of patients did not experience a decline in cognitive function at 6 months post TAVI procedure. This finding, in conjunction with the reassurance that detectable "silent" infarcts following TAVI are not associated with cognitive decline, is encouraging for patients hoping to avoid cognitive decline following such an important procedure. The finding in our study that TAVI is not associated with cognitive decline beyond discharge is consistent with findings from other studies in the literature [8-19], and is reassuring for those patients who are fearful of experiencing adverse neuro cognitive issues following replacement of their aortic valve.

The majority of studies have evaluated cognitive function following TAVI using either the MMSE or another form of cognitive evaluation [6-14]. Few studies [16-19] have used the Montreal Cognitive Assessment, a more sensitive tool for detection of mild cognitive impairment in comparison to the MMSE [20]. The MoCA is recommended by the National Institute of Neurologic Disorders and Stroke-Canadian Stroke Network (NINDS-CSN) in this patient population. Our findings are consistent with previous studies using the MoCA which have demonstrated improvement in MoCA scores at 30 days [18,19], 3 months [17] and at 1 year [16], particularly those who were cognitively impaired at baseline $[16,18]$.

It has been postulated that the relief of aortic valve obstruction, by improving cardiac output and possibly cerebral perfusion, could potentially improve cognitive function. In an attempt to evaluate predictors of cognitive improvement and decline following TAVI, Shoenenberger et al. [35] in an analysis of 229 patients who underwent cognitive evaluation using the MMSE, smaller AVA was found to be associated with patients who experienced cognitive improvement compared to those who did not experience cognitive improvement [35]. This may be due to improvement in cerebral perfusion, as patients who are cognitively impaired at baseline may be more sensitive to decreased cerebral perfusion and may be more likely to benefit from the TAVI procedure.

This study has several limitations. First, while this is the largest TAVI cohort to undergo neurologic evaluation with the MoCA test, the follow up is limited to 6 months. Other studies have confirmed preserved neurological status at 1 [16] and 2 [8] years. As TAVI use is expanded to lower risk patients, information regarding longer term follow up will be warranted. Second, cerebral imaging was not performed, which could be used to correlate with cognitive function outcomes. However, as discussed above, studies have consistently failed to demonstrate a relationship between clinically silent cerebral infarcts and neuro cognitive decline in TAVI patients $[9,11,14,26]$.

Despite this, recent studies on the use of cerebral embolic protection devices have demonstrated greater cognitive improvement in patients in which a protection device was used $[18,19]$, suggesting further research into the interplay between emboli and cognitive function in the setting of TAVI is needed. Finally, as Trans catheter devices evolve, there will be a constant paucity of data on current devices, limiting applicability in current practice. Nonetheless, this study in conjunction with current literature is reassuring in the preservation and probable amelioration of cognitive function in patients undergoing TAVI.

\section{Conclusion}

In conclusion, this study is reassuring in its finding that patients undergoing TAVI did not experience postoperative cognitive decline. Furthermore, it found that TAVI was associated with improvement in cognitive function among patients who were impaired at baseline. It is anticipated that these results may be used to guide patient selection and discussion around cognitive outcomes in this high-risk patient cohort. Further research into predictors of early cognitive decline in these patients is warranted in larger cohorts.

\section{References}

1. Leon MB, Smith CR, Mack M, Miller DC, Moses JW, et al. (2010) Transcatheter aortic-valve implantation for aortic stenosis in patients who cannot undergo surgery. New Eng J Med 363(17): 1597-1607.

2. Mahanna EP, Blumenthal JA, White WD, Croughwell ND, Clancy CP, et al. (1996) Defining neuropsychological dysfunction after coronary artery bypass grafting. Ann Thorac Surg 61(5): 1342-1347.

3. Newman MF, Grocott HP, Mathew JP, White WD, Landolfo K, et al. (2001) Report of the Substudy Assessing the Impact of Neurocognitive Function on Quality of Life 5 Years After Cardiac Surgery. Stroke 32(12): 2874-2881. 
4. Roach GW, Kanchuger M, Mangano CM, Newman M, Nussmeier N, et al. (1996) Adverse Cerebral Outcomes after Coronary Bypass Surgery. New Eng J Med 335(25): 1857-1863.

5. van Dijk D, Keizer AMA, Diephuis JC, Durand C, Vos LJ, et al. (2000) Neurocognitive dysfunction after coronary artery bypass surgery: A systematic review. J Thorac Cardiovasc Surg 120(4): 632-639.

6. Alassar A, Soppa G, Edsell M, Rich P, Roy D, et al. (2015) Incidence and Mechanisms of Cerebral Ischemia After Transcatheter Aortic Valve Implantation Compared With Surgical Aortic Valve Replacement. Ann Thorac Surg 99(3): 802-808.

7. Abdul-Jawad Altisent O, Ferreira-Gonzalez I, Marsal JR, Ribera A, Auger C, et al. (2016) Neurological damage after transcatheter aortic valve implantation compared with surgical aortic valve replacement in intermediate risk patients. Clin Res Cardiol 105(6): 508-517.

8. Ghanem A, Kocurek J, Sinning JM, Wagner M, Becker BV, et al. (2013) Cognitive Trajectory After Transcatheter Aortic Valve Implantation. Circ Cardiovasc Interv 6(6): 615-624.

9. Gleason TG, Schindler JT, Adams DH, Reardon MJ, Kleiman NS, et al (2016) The risk and extent of neurologic events are equivalent for high-risk patients treated with transcatheter or surgical aortic valve replacement. J Thorac Cardiovasc Surg 152(1): 85-96.

10. Holinski S, Staebe P, Geyer T, Neumann K, Uebelhack R, et al. (2013) Transfemoral Versus Conventional Aortic Valve Implantation-Early Postoperative Cognitive Outcome. Ann Thorac Cardiovasc Surg 19(3): 195-200.

11. Kahlert P, Knipp SC, Schlamann M, Thielmann M, Al Rashid F, et al (2010) Silent and Apparent Cerebral Ischemia After Percutaneous Transfemoral Aortic Valve Implantation: A Diffusion-Weighted Magnetic Resonance Imaging Study. Circulation 121(7): 870-878.

12. Knipp SC, Kahlert P, Jokisch D, Schlamann M, Wendt D, et al. (2013) Cognitive function after transapical aortic valve implantation: a singlecentre study with 3-month follow-up. Interact Cardio Vasc Thorac Surg 16(2): 116-122.

13. Orvin K, Dvir D, Weiss A, Assali A, Vaknin Assa H, et al. (2014) Comprehensive Prospective Cognitive and Physical Function Assessment in Elderly Patients Undergoing Transcatheter Aortic Valve Implantation. Cardiology 127(4): 227-235.

14. Rodés-Cabau J, Dumont E, Boone RH, Larose E, Bagur R, et al. (2011) Cerebral Embolism Following Transcatheter Aortic Valve ImplantationComparison of Transfemoral and Transapical Approaches. J Am Coll Cardiol 57(1): 18-28.

15. Lai KSP, Herrmann N, Saleem M, Lanctôt KL (2015) Cognitive Outcomes following Transcatheter Aortic Valve Implantation: A Systematic Review. Cardiovasc Psychiatry Neurol 2015.

16. Auffret V, Campelo-Parada F, Regueiro A, Del Trigo M, Chiche O, et al. (2016) Serial changes in cognitive function following transcatheter aortic valve replacement. J Am Coll Cardiol 68(20): 2129-2141.

17. Kahlert P, Al-Rashid F, Döttger P, Mori K, Plicht B, et al. (2012) Cerebral Embolization During Transcatheter Aortic Valve Implantation A Transcranial Doppler Study. Circulation 126(10): 1245-1255.

18. Lansky AJ, Schofer J, Tchetche D, Stella P, Pietras CG, et al. (2015) A prospective randomized evaluation of the TriGuard ${ }^{\text {TM }} \mathrm{HDH}$ embolic DEFLECTion device during transcatheter aortic valve implantation: results from the DEFLECT III trial. Eur Heart J 36(31): 2070-2078.

19. Rodés-Cabau J, Kahlert P, Neumann FJ, Schymik G, Webb JG, et al. (2014) Feasibility and exploratory efficacy evaluation of the Embrella Embolic Deflector system for the prevention of cerebral emboli in patients undergoing transcatheter aortic valve replacement: the PROTAVI-C pilot study. JACC Cardiovasc Inter 7(10): 1146-1155.
20. Nasreddine ZS, Phillips NA, Bédirian V, Charbonneau S, Whitehead V, et al. (2005) The Montreal Cognitive Assessment, MoCA: a brief screening tool for mild cognitive impairment. J Am Geriatr Soc 53(4): 695-699.

21. Newman MF, Kirchner JL, Phillips Bute B, Gaver V, Grocott H, et al. (2001) Longitudinal assessment of neurocognitive function after coronary-artery bypass surgery. New Eng J Med 344(6): 395-402.

22. Barber PA, Hach S, Tippett LJ, Ross L, Merry AF, et al. (2008) Cerebral ischemic lesions on diffusion-weighted imaging are associated with neurocognitive decline after cardiac surgery. Stroke 39(5): 1427-1433.

23. Floyd TF, Shah PN, Price CC, Harris F, Ratcliffe SJ, et al. (2006) Clinically silent cerebral ischemic events after cardiac surgery: their incidence, regional vascular occurrence, and procedural dependence. Ann Thorac Surg 81(6): 2160-2166.

24. Gerriets T, Schwarz N, Bachmann G, Kaps M, Kloevekorn WP, et al. (2010) Evaluation of methods to predict early long-term neurobehavioral outcome after coronary artery bypass grafting. Am J Cardiol 105(8): 1095-1101.

25. Goto T, Baba T, Honma K, Shibata Y, Arai Y, et al. (2001) Magnetic resonance imaging findings and postoperative neurologic dysfunction in elderly patients undergoing coronary artery bypass grafting. Ann Thorac Surg 72(1): 137-142.

26. Knipp SC, Matatko N, Schlamann M, Wilhelm H, Thielmann M, et al. (2005) Small ischemic brain lesions after cardiac valve replacement detected by diffusion-weighted magnetic resonance imaging: relation to neurocognitive function. Eur J Cardiothorac Surg 28(1): 88-96.

27. Restrepo L, Wityk RJ, Grega MA, Borowicz L, Barker PB, et al. (2002) Diffusion-and perfusion-weighted magnetic resonance imaging of the brain before and after coronary artery bypass grafting surgery. Stroke 33(12): 2909-2915.

28. Pugsley W, Klinger L, Paschalis C, Treasure T, Harrison M, et al. (1994) The impact of microemboli during cardiopulmonary bypass on neuropsychological functioning. Stroke 25(7): 1393-1399.

29. Bendszus M, Reents W, Franke D, Müllges W, Babin Ebell J, et al. (2002) Brain damage after coronary artery bypass grafting. Arch Neurol 59(7): 1090-1095.

30. Arnold M, Schulz Heise S, Achenbach S, Ott S, Dörfler A, et al. (2010) Embolic cerebral insults after transapical aortic valve implantation detected by magnetic resonance imaging. JACC Cardiovasc Interv 3(11): 1126-1132.

31. Astarci P, Glineur D, Kefer J, D Hoore W, Renkin J, et al. (2011) Magnetic resonance imaging evaluation of cerebral embolization during percutaneous aortic valve implantation: comparison of transfemoral and trans-apical approaches using Edwards Sapiens valve. Eur J Cardiothoracic Surg 40(2): 475-479.

32. Fairbairn TA, Mather AN, Bijsterveld P, Worthy G, Currie S, et al. (2012) Diffusion-weighted MRI determined cerebral embolic infarction following transcatheter aortic valve implantation: assessment of predictive risk factors and the relationship to subsequent health status. Heart 98(1): 18-23.

33. Ghanem A, Müller A, Nähle CP, Kocurek J, Werner N, et al. (2010) Risk and fate of cerebral embolism after transfemoral aortic valve implantationA prospective pilot study with diffusion-weighted magnetic resonance imaging. J Am Coll Cardiol 55(14): 1427-1432.

34. StolzE, Gerriets T, Kluge A, Klövekorn WP, Kaps M, etal. (2004) Diffusionweighted magnetic resonance imaging and neurobiochemical markers after aortic valve replacement implications for future neuroprotective trials? Stroke 35(4): 888-892.

35. Schoenenberger AW, Zuber C, Moser A, Zwahlen M, Wenaweser P, et al. (2016) Evolution of Cognitive Function After Transcatheter Aortic Valve Implantation. Circ Cardiovasc Interv 9(10): e003590. 
Your next submission with JuniperPublishers will reach you the below assets

- Quality Editorial service

- Swift Peer Review

- Reprints availability

- E-prints Service

- Manuscript Podcast for convenient understanding

- Global attainment for your research

- Manuscript accessibility in different formats (Pdf, E-pub, Full Text, Audio)

- Unceasing customer service 